\title{
Strategies for Effective School Leadership
}

\author{
John Nikolaros \\ Department of Education, Harry S. Truman College \\ 1145 W. Wilson Ave Chicago, IL 60074, United States \\ Tel: 1-773-907-4000Ｅ-mail: jnikolaros@ccc.edu
}

Received: March 29, 2015

Accepted: May 4, 2015

Published: May 25, 2015

doi:10.5296/gjes.v1i1.7557

URL: http://dx.doi.org/10.5296/gjes.v1i1.7557

\begin{abstract}
To many, effective leadership is continently appropriate as conscience. The paper identifies strategies that assists schools facilitate a warmer and healthier school environment. The author provides a review of delineated leadership strategies with a narrative for each type. Highlighting different cultures and assumptive impact on school culture and climate is offered.
\end{abstract}

Keywords: Leadership, Principle, Strategies 


\section{Introduction}

According to Notman and Henry (2010), effective principals use multiple leadership strategies for leading teachers to raised levels of student achievement. The following are leadership strategies used by principals. (a) vision and purpose, (b) focus on student achievement, (c) school improvement practices, (d) consultation with teachers and community, (e) employment of quality staff, (f) strong senior leadership team, (g) personnel support systems, (h) integration of different cultures, (i) growing other leaders, (j) and "hands on the turbine" (i.e. ecosystem).

\section{Principle}

A critical leadership skill for successful principals is decision making. When staff and line employees collaborate on decision-making, leadership is imperative to substantiation, which affects the school (Crum, Sherman, \& Myran, 2009). The principal if decides to decide on issues independently, this could allow for a state of higher questionability and accuracy. My recommendation is to permit teachers and high-qualified staff to assist in decision-making and work as a team of councils to provide possible solutions to problems. This effective leadership impulse helps leaders to manage effectively (Yukl, 2009); express an axis or structure for group resiliency and decision-making. By implementing group resiliency, the traditional definition of management, which insists to control, eliminates properly and staff assimilates a self-assessment of management.

A group decision-making model is one of many components of distributive leadership. Successful principals seek to form partnerships with all key stakeholders acknowledging their perspectives. Distributive leadership focuses on collaboration, shared purpose, responsibility, and recognition of leadership irrespective of role or position within an organization (Keppell, O'Dwyer, Lyon, \& Childs, 2010). The premise of 'distributive leadership' encompasses the notion of collaboration by many rather than one central authority figure. Connotations emphasize a collegial sharing of knowledge, practice and reflection, dissemination of strategies to the group, and deduces horizontal models of leadership (Ylimaki \& Jacobson, 2013). Successful leadership implementation applies the broad intent and principles of distributive leadership towards the vision and 'capacity building' of curriculum and instruction. Seemingly, educational governance understands the importance of training and skill development for educational stakeholders to assume leadership responsibility, and that the concept of distributed leadership exposed staff to new ideas and participation in knowledge creation and transfer (Davies \& Davies, 2006).

My contention supports the design of placing teachers in small learning communities within the school. Large department meetings do not inspire staff to express their particular ideas and for the most part seclude their ideas. This, then causes an unhealthy ethos of expression and results in negativity towards the ideas of others. In smaller groups, even within departments, there are more opportunities for all staff to contribute and express ideas, that in larger meetings could have been kept private. The impact is highly valued in successful school environments when staff communicates even if there ideas are reconceptualized. 


\section{$\Lambda$ Macrothink}

Global Journal of Educational Studies

ISSN 2377-3936

2015, Vol. 1, No. 1

The collaborative engagement of the group is the first and foremost priority for school principals. With engagement serving sufficient quantity, the next principle is assessing the quality of engagement. Successful principals must determine their precise level of supervision. This is when to lead from behind, from the middle, or lead in the front. In some cases when staff exhibit effective/efficient, substantive participation, leaders only need to observe and serve with presence. The level of supervision defines a leader's ability to encapsulate and de encapsulates learning processes. A leader is effective or ineffective due to his or her ability to act when prompted. The decision to implement sequential concurrence or extinctive supervision could increase or detract from the effectiveness of group dynamics depending on the situation. The goal is to reject the idea, to unduly mislead staff, in anyway using a particular leadership technique.

\section{Leadership Strategies}

School vision must support student learning. A comprehensive school programming process affords a symbiosis between curriculum, instruction, assessment, and implementation must polyexist within successful school environments. A delineated purpose identifiable along with a process of how to meet school functional-practical, and intangible needs pertaining to the improvement of student achievement. A vision serving purpose takes in consideration of subsequent skills, attitudes, aptitudes and how those dispositions impact school programming. The associative properties of vertical and horizontal integration articulate prognosis and diagnosis of student learning, while this synergism can streamline identified issues and closely guide implementation efforts.

Student achievement is a predictor of school proximity and regulation. The foci for raising student achievement are central, legal proposition for school leadership. Within this paradigm, an accurate evaluation of student skills premeditates student performances on multiple types of assessments. Effective leaders improve student outcomes on state-standardized testing. State-standardized testing although on its own does not truly forecast a conclusive pulse of student achievement. There are limitations and assumptions that state-standardized testing do not weigh in student growth and critical thinking skills. Principals must conclusively render all factors that produce successful student outcomes. Defined, students achievement as several external and internal contingencies that help children reach their highest potential, to contribute productively in society. That is not only a premise on raising students' state standardized testing but also target others factors such as graduation and attendance rate, parent involvement, and the acceptance and the rate of longevity, as well as the successful completion of a college degree.

School improvement practices exemplify high utility and fidelity on addressing specific AYP targets goals. Schools internally sample and specify areas of improvements feasibly apply an identity through data and assessment. The identification of school-wide improvements sets the stage for implicit, specialized initiatives. For effective school improvement, principals must closely intertwine and, with relevancy assess curriculum and instruction: theory, strategy, and implementation. In this process, we see cohesion, heterogeneous application among each agency. This then, provides transparency for the organization and staff members. 
Inconsistent methods in either agency of theory, strategy, and implementation could mark sustainability parameters as invalid or unreliable, as well as advocate the inflation of student performances (Liethwood et al., 2010). The objective notion for school leaders is to embrace their schools inadequacies and not evaluate them as weaknesses. These impediments are opportunities for change and successful leadership. Among other quotients, the askance of change imposes acute nominations or recommendation; and hence the inconclusive past school participles (e.g. transgressions), add to ideas' plausibility.

The idea of consulting with teachers and the community predicated on decisions that prosperity influence the school builds interdependence among stakeholders. The consolation is an effect of respect that contributes to the school. More group resiliency and determination for a shared vision of the school will partake when ideas and insights are considered and received. Each stakeholder in some capacity is shaping and assisting the school's system functionalities within different contexts. More importantly, the community accounts for a high majority of financial derivative needed to fund educational expenses. My experiences are that community members are open to be consulted, and it is the job of school leadership to bridge this gap by reaching out to them.

The hiring of quality staff members, although is difficult to truly predict and assess the quality of a staff member initially and if presumed ineffective, can preclude a negative embodiment-transference when starting the school year (Jacobson, 2005). So much of effective implementation of curriculum and instruction necessitates with school leaders and teachers setting a persuading rhetoric, confining tone for learning early on in the school year. The hiring of quality staff in turn creates a conducive learning environment that confirms the leadership skills of the principal. By so, the hiring principal can demonstrate a proficient level of assessing teacher skills and capacity. The principal has the power to begin leadership deliverance during the interview process. Within the interview, the successful principal should be able to efficiently detect a strong candidate and a weak candidate as well. The importance of hiring quality staff is highly attributable to the success of schools. Most keenly, the poor identification of one quality staff member can reach out to many and, ultimately divulge from the school and group dynamics and, further inhibit progressive admonitions of school leadership and staff.

District administration, in addition, plays a vital role in successful leadership at the building level. They essentially provide internal accountability for their administrative team. Principals just like any other staff member must meet expectations and criteria set forth by district educational management personnel. A strong district administration team can offer a 'second set of eyes' for principals pertaining to matters that need consultation. The district administration team must possess previous principalship experience. Therefore, are sources of sound, valid, and reliable operative for principals. They need to ascertain the confidence of the principals so they can feel comfortable polling their advice. A senior educational management team must be knowledgeable in curriculum and instruction, day-to-day operations, and legality issues related to school management and implementation. It is added transparency for district administration to be competent in special education law, eligibility, identification, and assessment. Additively, successful school implementation falls under 
facilitating special education programs symmetrical-compliant to state and national legislation and bodies. Schools who follow strict guidelines create internal efficacy and accountability for all staff and programs.

Support systems are impetus resolvedly implemented directly or indirectly. Personnel-curricular support systems espouse a collaborative environment based on lifelong learning. Direct support systems are groups, committees or designated instructional coaches or itinerants that provide professional development, instruction, or training for staff members. For example, school hire instructional coaches to assist teachers with operants related to the academic and social/emotional success of their students. Indirect support systems are resources from administration, teachers, or support staff in the form of informational data. For example, formulae of indirect support systems are school report cards that provide data about testing and other data of scalability (i.e. years of teaching experience, percentage of teachers with higher degrees) and student forms of data, (i.e. performance on different types of state standardized testing; and (content assessment) graduation rate, and attendance). Teachers are prone to modify and identify curricular changes from the precision of both models. The articulation and alignment of both models provides more in-depth reflection and synthesize of oneself and school programming.

The integration of different cultures enhances school diversity (Nir, 2001). Thematic consternations valuing and embracing differences supports the overall success of schools. Include, as such themes as recognizing the basic value and rights of each individual, taking the standpoint of others into consideration, deliberation in making decisions, embracing plurality and difference, and promoting equity and social justice (Moller, 2006). The rights of each individual to accept differences and orientate with other staff an acceptance of diversity sets up the stage for effective relationships which leads to a cohesive school environment. The counter argumentation of self when communicating, along with acknowledging other's views proves to be helpful in opening stereotypes linked to self, other people, and the school. Plurality, the voice for exceptionality, to relinquish egotistical semantic traits, explores the differences not only in absolute identification, but in all ideological syncretic intelligences. Such differences in eye color, dress, tone, persona, charisma, perspectives, and much more elevate epistemology to reexamine the basic affect of learning (Hajisoteriou \& Angelides, 2014).

Teacher leadership is an important part of building successful schools. Principals must instill the derivative of leadership within each teacher. The etymological leadership aptitude, a developmental process beginning in the early stages of a teacher's career. Effective principals identify teachers' strengths, to hone their skills, as well as bring to the discussion their weaknesses. Progressively, weaknesses are aspirations and not inadequacies, while many teachers do not disclose them or are hesitant to express them, because of the negative merits it distinguishes on each teacher. A finite, closed perception of a teacher's skill should not be undertaken after the teacher demonstrates or expresses, of a weakness. Effective principals construct the effectiveness of performance through growth and development. If the advent assessment of human skills is growth from one presence to a delineated impression, principals evaluate and perceive teachers merits and value albeit to principles of development 
and maturation.

The cliché of having one's 'hands on the turbine' implies to leadership knowledge of implementation that directly leads to successful school management. Principals seen as supervisors 'behind the scenes' or silent managers are not effective in making a profound impact towards their school success. Being involved and most importantly visible in departmental transparency and a contributor to decentralization can provide much needed information about the school's primary agency of success. The principal must comprehend the notion that improving the school stature involves the utilization, collaborative process. The pulse of the school disseminates within the constructs of the classroom. The principal's awareness and conscious internalization for the purpose, thorough acclimation, of his or her understanding of each classroom guides subsequent professional development and school improvement. Such to, with data from testing, principals must acquire corroborated evidence of school improvement from observations and communications from important constituents within the schools operations.

The change process requires a transformational approach to leadership. This approach values the competencies of each staff member and aligns implementation to prescribe each members abilities. The center delivery of policy must concomitantly impinge within all members of the culture. The implementation must change accountability subsuming the internal context. Teachers are vital contextual imprints to exude the buy in principles of change as well as the community. The audiences must see in their own turns the successes when change is adopted. This affective process of change extracts the substantive control from the leadership to the subordinates. The agency of its propositions require a permutation of leadership and intrinsic facilitation of persuasion. The encouragement to teachers from teachers will resonate with transparency holding more contention for change over longer periods of time.

\section{Conclusion}

Leaders must exhibit a strong sense of self-being within school and community eliminating the inclination of self-regard or admiration. The effective leader denotes an embodiment for the external contingency of the group in this case is the school and community members. Internal repose will signify a leadership agenda rooted in the individual and moralizing the power of self in leadership which is the antithesis of successful leadership. The delineation must be cemented, a teacher autonomy, and all conscientious external memberships. The power mentioned is utilizing in a facilitation of professional wisdom and creativity to constructively cultivate the learning environment. The disapproval of the leadership principality, for investigating teacher premise and contrarian ideology to result in reflective assessment and evaluation is allowed.

\section{References}

Crum, K. S., Sherman, W. H., \& Myran, S. (2009). Best practices of successful elementary school leaders. Journal of Educational Administration, 48(1), 48-63. http://dx.doi.org/10.1108/09578231011015412

Davies, B., \& Davies, B. (2006). Developing a model for strategic leadership in schools. 
Educational Management Administration Leadership, 34(1), 121-139. http://dx.doi.org/10.1177/1741143206059542

Hajisoteriou, C., \& Angelides, P. (2014). Facing the 'challenge': School leadership in intercultural schools. Educational Management Administration \& Leadership, (42), 65-82. http://dx.doi.org/10.1177/1741143213502194

Jacobson, S. (2005). The recruitment and retention of school leaders: Understanding administrator supply and demand. London: Kluwer Press.

Johnson, L., Moller, J., Pashiardis, P., Vedoy, G., \& Sawides, V. (2011). Culturally responsive practices. US and Cross-National Policies, Practices, and Preparation Studies in Educational Leadership, 12, 75-101. http://dx.doi.org/10.1007/978-94-007-0542-5_5

Keppell, M., O’Dwyer, C., Lyon, B., Childs, M. (2010). Transforming distance education curricula through distributive leadership. The Journal of the Association for Learning Technology, 18(3), 165-178.

Leithwood, K., Anderson, S., Mascall, B., \& Straus, T. (2010). School leaders' influences on student learning: The four paths. In Bush, T., Bell, L., \& Middlewood, D.(Eds), The Principles of Educational Leadership and Management. London: Sage.

Nir, A. E. (2001). Administrators' perceived role vulnerability - a comparison of centralized domesticated and decentralized undomesticated organizations. Journal of Educational Administration, 39(2), 134-147. http://dx.doi.org/10.1108/09578230110386269

Notman, R., \& Henry, A. D. (2010). Building and sustaining successful school leadership in New Zealand. Leadership and Policy in Schools, 10(4), 375-394. http://dx.doi.org/10.1080/15700763.2011.610555

Ylimaki, R., \& Jacobson, S. (2013). School leadership practice and preparation. Journal of Educational Administration, 51(1), 6-23. http://dx.doi.org/10.1108/09578231311291404

Yuki, G. (2009). Leading organizational learning: Reflections on theory and research. The Leadership Quarterly, 20(1), 49-53. http://dx.doi.org/10.1016/j.leaqua.2008.11.006

\section{Copyright Disclaimer}

Copyright for this article is retained by the author(s), with first publication rights granted to the journal.

This is an open-access article distributed under the terms and conditions of the Creative Commons Attribution license (http://creativecommons.org/licenses/by/3.0/). 